\title{
Anosmia-hyposmia and dysgeusia in COVID-19 may be due to SARS-CoV-2 protein mimicry of olfactory receptors*
}

\section{Robert Root-Bernstein}

Michigan State University, Department of Physiology, East Lansing, MI 48824 USA
Rhinology Online, Vol 3: 148 - 151, 2020

http://doi.org/10.4193/RHINOL/20.063

*Received for publication:

August 25, 2020

Accepted: September 23, 2020

Published: September 27, 2020

\begin{abstract}
Background: Anosmia-hyposmia and dysgeusia are common symptoms of mild-to-moderate COVID-19 cases. They are usually, but not always, reversible and the cause is unknown.
\end{abstract}

Methodology: Proteonomic similarity searching (BLAST) was used to test whether SARS-CoV-2 has an unusual degree of similarity to human olfactory receptors as compared with other viruses.

Results: SARS-CoV-2 displays two orders of magnitude more similarities to human olfactory receptors than does any other upper respiratory virus or rhinovirus and five times as many similarities as cold-causing coronaviruses.

Conclusions: It is hypothesized that IgA antibodies produced against SARS-CoV-2 proteins and secreted in saliva and mucus bind to and block human olfactory receptors. These antibodies cause the reversible form of anosmia-hyposmia associated with COVID-19 infection. The mimicry may also, rarely, lead to autoimmune disease against neurons expressing olfactory receptors, in which case oral or nasal steroids may be therapeutic.

Key words: SARS-CoV-2, COVID-19, olfactory, smell, taste, molecular mimicry, lgA, autoimmunity, autoimmune disease, immunity, cross-reactivity

\section{Introduction}

Loss of smell and taste (anosmia or hyposmia) and/or taste (dysgeusia) are now recognized to be significant, often presenting, clinical features of mild-to-moderate SARS-CoV-2 infection affecting, on average, more than $50 \%$ of patients (range 5 to $98 \%$ in different studies) with a preponderance in women (ca. $70 \%$ ) and individuals under the age of 50 (e.g., ${ }^{(1,2)}$ ). Various hypotheses have been proffered to explain the loss of olfactory receptor function including direct infection of olfactory neurons; infection of sustentacular (neuronal support) cells resulting in loss of olfactory receptor-containing cilia; and local inflammation of the olfactory epithelium (reviewed in ${ }^{(3)}$ ) but no definitive explanation yet exists. Evidence is presented here that SARSCoV-2 proteins exhibit multiple sequences that mimic highly conserved extracellular loop and binding regions of human olfactory proteins. It is hypothesized that these SARS-CoV-2 antigens induce immunoglobulin type $A(\lg A)$, that is released into saliva, mucus and tears to control the infection but which also bind to and block olfactory receptors.

\section{Materials and methods}

BLASTP (version 2.2.31+) on the www.expasy.org website was used to search for possible similarities between the entire sequences of SARS-CoV-2 proteins and human olfactory receptors with the following settings: BLOSUM 80 was used to identify short sequences such as those presented by human leukocyte antigens and recognized by $T$ cell receptors; gaps disallowed; low complexity regions screened out; $E$ set to 1000 with 3000 best matches displayed. All SARS-CoV-2 proteins were tested along with those of coronavirus HKU1, SARS-CoV-1, Middle 
Table 1. Summary of BLAST results comparing virus proteomes with human olfactory receptors." Unique sequences" are similarities that are distinct in the region of the olfactory receptor that any given virus protein matches. In most cases, a given virus protein matched more than one olfactory receptor, which is indicated in the number of "total matches".

\begin{tabular}{|c|c|c|}
\hline Viral genome & $\begin{array}{l}\text { Unique } \\
\text { sequences }\end{array}$ & $\begin{array}{c}\text { Total } \\
\text { matches }\end{array}$ \\
\hline Coxsackievirus A9 I6VPA8 & 0 & 0 \\
\hline Coxsackievirus B3 P03313 & 0 & 0 \\
\hline Echovirus E6 K4MI18 & 0 & 0 \\
\hline Enterovirus E A0A193AUM2 & 0 & 0 \\
\hline Hepatitis A Virus P06441 & 1 & 5 \\
\hline HIV-1 group M subtype $B^{\wedge}$ & 2 & 7 \\
\hline Influenza H1N1 Wilson@ & 3 & 4 \\
\hline Poliovirus Type 1 P03300 & 0 & 0 \\
\hline Rhinovirus 1A P23008 & 1 & 2 \\
\hline Rhinovirus 2 P04936 & 0 & 0 \\
\hline Rhinovirus C3 A0A5Q0QNI0 & 1 & 2 \\
\hline Rhinovirus 14 P03303 & 0 & 0 \\
\hline Rhinovirus 16 Q82122 & 1 & 2 \\
\hline AVERAGE & 0.7 & 1.7 \\
\hline Coronavirus HKU1 (isolate N1) \# & 14 & 48 \\
\hline $\begin{array}{l}\text { MERS (isolate United Kingdom/ } \\
\mathrm{H} 123990006 / 2012)+\end{array}$ & 15 & 54 \\
\hline Human SARS coronavirus (SARS-CoV) ${ }^{\%}$ & 21 & 233 \\
\hline Human SARS-CoV-2 & 23 & 203 \\
\hline Replicase 1a PODTC1 & 1 & 2 \\
\hline Spike Protein PODTC2 & 1 & 1 \\
\hline Protein 3a PODTC3 & 0 & 0 \\
\hline Small Envelope Protein PODTC4 & 4 & 14 \\
\hline Membrane Protein PODTC5 & 4 & 10 \\
\hline Non-Structural Protein PODTC6 & 2 & 3 \\
\hline Protein 7a PODTC7 & 9 & 168 \\
\hline Protein 8 PODTC8 & 0 & 0 \\
\hline Nucleoprotein PODTC9 & 0 & 0 \\
\hline Replicase 1ab P0DTD1 \& & 1 & 2 \\
\hline Protein 9b P0DTD2 & 1 & 3 \\
\hline Protein NS14 P0DTD3 & 0 & 0 \\
\hline Protein 7b P0DTD8 & 0 & 0 \\
\hline
\end{tabular}

UniProt accession numbers are provided for each virus proteome utilized in the searches: ${ }^{\circledR}$ P03470, P05777, P03427, P03430, P05777, P03454, Q82506, P15659, P15682. " P0C6X2, Q5MQD0, Q5MQD1, Q5MQC7, Q5MQC6, Q5MQC8, Q5MQC5, Q5MQC9; \% P59635, P59632, P59594, P59637, P59595, P0C6X7, P59636, P59634, P59596, P59633. Q80H93, Q7TFA1, Q7TLC7, Q7TFA0; ' K9N7C7, K9N5Q8, K9N7A1, K9N643, K9N4V0, K9N5R3, K9N4V7, K9N7D2, K9N796; ^ P04585, K7X064, P69726, A0EVB9, P05919, O43719, P04618, P69723 \& P0DTD1 overlaps P0DTC1 so only additional matches are listed in this row.
East Respiratory Syndrome virus (MERS), and seventeen control virus proteomes including multiple rhinoviruses associated with anosmia $^{(4)}$ (Table 1). Results were further screened by identifying the location of the match on the presumed 3D structure of olfactory receptors as provided in the UniProt accession data (Figure 1). Statistics were not run since the results are so intrinsically obvious.

\section{Results}

SARS-CoV-2 proteins exhibited almost two orders of magnitude greater numbers of similarities to human olfactory proteins than did any other virus tested except for the coronavirus HKU1 (a cold virus), SARS-CoV-1 and MERS. Controls were mainly other respiratory viruses including influenza $\mathrm{H} 1 \mathrm{~N} 1$ (which was typical of other influenza viruses, not shown), coxsackieviruses (only two shown), and rhinoviruses four of which are presented. Most SARS-CoV-2 similarities were associated with the small envelope protein (PODTC4), membrane protein (PODTC5), and protein 7a (PODTC7), which mimicked extracellular and transmembrane binding regions of more than two hundred different human olfactory receptors. The same pattern was duplicated in SARSCoV-1 and MERS, which were also characterized by anosmia/ hyposmia ${ }^{(4)}$. This highly conserved mimicry would assure broad loss of olfaction. It is unlikely that cytoplasmic regions of similarity (Figure 1) are accessible to antibodies though they might become so during autoimmune disease.

The vast majority of the sequence similarities between SARSCoV-2 proteins and olfactory receptors (and all of those shown in Figure 1) satisfy the criterion that at least six of the amino acids in a sequence of ten are identical (where a pair of acceptable substitutions counts as one identity), making them excellent candidates for antigenic cross-reactivity as determined previously by experiment ${ }^{(5)}$.

\section{Discussion}

Infection with SARS-CoV-2 elicits early, high titers of immunoglobulin type $\mathrm{A}(\lg \mathrm{A})$ antibodies that rapidly decrease after the virus is eliminated with a titer half-life of about ten days ${ }^{(6)}$. These $\lg \mathrm{A}$ antibodies are the primary means of virus neutralization in mucosa ${ }^{(7)}$. I propose the novel hypothesis that IgA cross-react with olfactory receptors blocking receptor function without killing the associated neurons. The better the immune response, the more complete the anosmia but, correspondingly, the better-controlled the infection. This hypothesis explains why gustatory and olfactory impairment are associated with mild to moderate COVID-19 symptoms ${ }^{(1,2)}$ and why most patients recover smell and taste within four weeks as the virus is cleared from the body and IgA antibody levels decrease ${ }^{(6,7)}$. The hypothesis is testable by examining the saliva of anosmic, hyposmic or dygeustic COVID-19 patients for IgA antibodies that bind to 


\section{PODTC4 54 PSFIVISRVKNLNSSRV 70 $\mathrm{P}++\mathrm{V}++\mathrm{NLNS}+\mathrm{RV}$ \\ huOLFR 11 PTEFVLAGLPNLNSARV 27 A0A126GWN5 EXTRACELUULAR N-TERM}

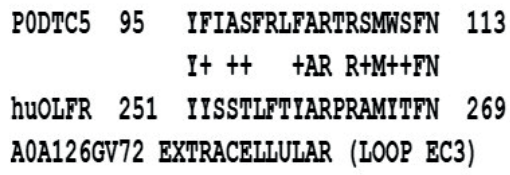

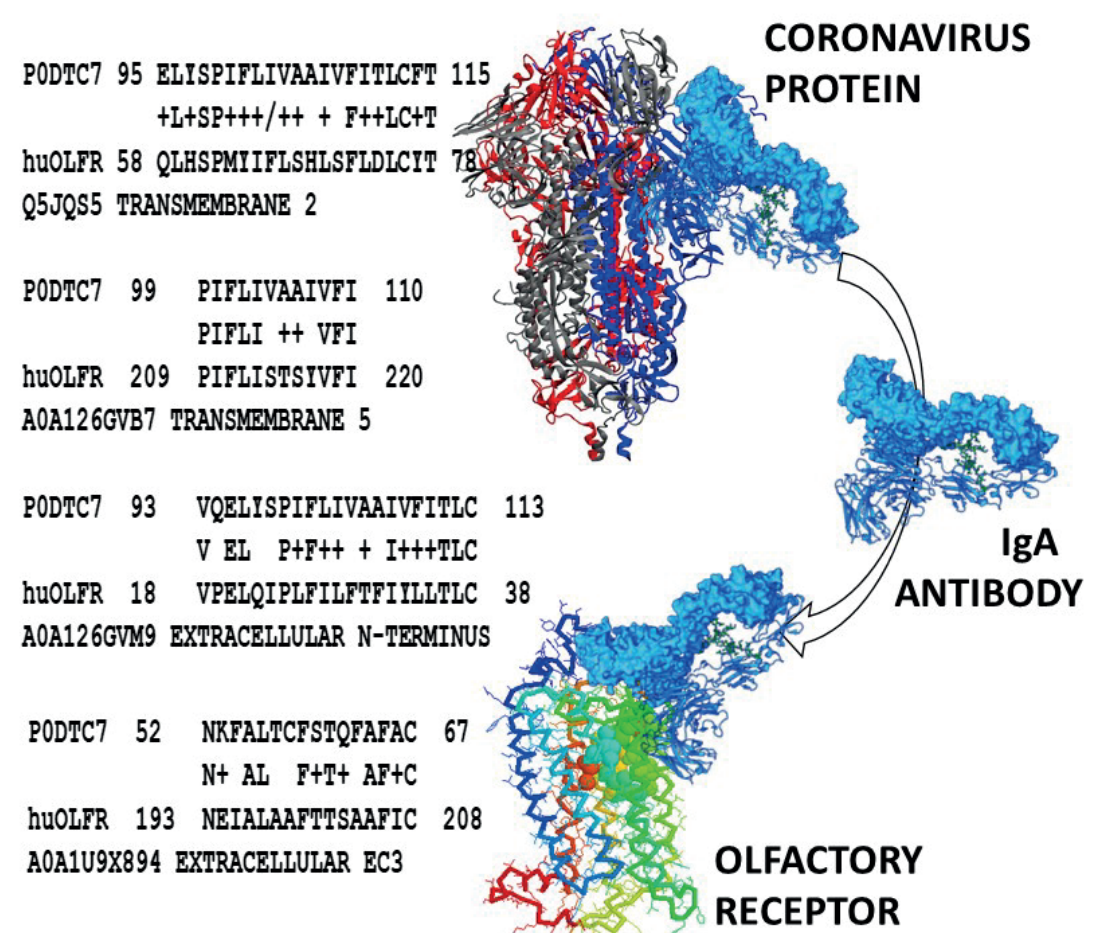

Figure 1. Left: Representative similarities between SARS-CoV-2 proteins and human olfactory receptors (huOLFR). + signs indicate homologous amino acid substitutions. Full SARS-CoV-2 protein names are provided in the Table. The UniProt accession number for the particular human olfactory receptor is provided below each match. However, note that all of these similarities were repeated up to fifty times in other olfactory receptor homologs indicating that the similarities are mainly to highly conserved receptor regions so that antibody against any one olfactory receptor has a good probability of binding to others as well. Note also that the location of the similarity on the olfactory receptor molecule is provided; additional similarities exist to extracellular, transmembrane and cytoplasmic regions of the huOLFR that are not shown. Those similarities that are extracellular or transmembrane are the most likely to be accessible to antibody and are also the regions most likely to interfere with odorant binding and the changes in receptor conformation required to transmit a binding signal. Right: A visual summary of the hypothesis proposed here that some IgA (and possibly IgG or IgM) antibodies elicited by SARS-CoV-2 and other coronaviruses may cross-react with olfactory receptors because of the similarities illustrated to the left. Antibody binding to the olfactory receptors blocks odorant binding and/or signaling as long as antibody titers are sufficiently high.

olfactory receptors. This hypothesis might also explain transient hyposmia and anosmia associated with colds associated with other coronaviruses and rhinoviruses.

A corollary to the hypothesis could explain why some COVID-19 patients (as many as $25 \%$ ) develop chronic anosmia or hyposmia that does not resolve even after three or more months ${ }^{\left({ }^{8}\right)}$. Such patients may develop an autoimmune disease against their olfactory neurons triggered by the molecular mimicry illustrated in Figure 1 between SARS-CoV-2 proteins and olfactory receptors. While molecular mimicry is often associated with induction of autoimmune diseases, however, it is generally considered to be insufficient to trigger disease ${ }^{(9)}$. Current theory suggests that molecular mimicry requires an associated bystander or complementary infection that prevents T-cell tolerization needed to protect "self" cells ${ }^{(9)}$. Patients experiencing chronic smell and taste loss may therefore differ from those with transient symptoms in having evidence of a viral or bacterial co-infection along with
SARS-CoV-2. Such patients should be tested for complementactivating autoantibodies with specificity to olfactory receptors and loss of T-cell tolerance to olfactory neurons.

Nasal or oral steroids might be useful in treating the autoimmune form of the disease after a patient has repeatedly tested negative for SARS-CoV-2 but are contraindicated during active infection and in cases of transient smell and taste loss because of interference with active immunity against SARS-CoV-2 ${ }^{(8)}$. Indeed, for most patients, a strong IgA response resulting in anosmia-hyposmia appears to be a predictor of mild COVID-19 symptoms $(1,2,6,7)$.

\section{Conclusions}

In sum, it is demonstrated that SARS-CoV-2 shares significant similarities with a huge number of human olfactory receptors and it is proposed that $\lg \mathrm{A}$ antibody produced in response to the viral infection then blocks these receptors. This explains 
both why the anosmia/hyposmia and dysgeusia are transient and associated with mild cases of COVID-19. The hypothesis also proposes that chronic ( $>3$ month) loss of smell and taste may be due to an autoimmune disease against olfactory neurons triggered by the SARS-CoV-2-olfactory receptor mimicry. The hypothesis may also apply to other coronaviruses that share many olfactory receptor similarities that are not present in most rhnioviruses, influenza viruses and other upper respiratory viruses. Means of distinguishing between the transient and autoimmune forms of anosmia/hyposmia are suggested as well as differences in treatment..

\section{Acknowledgments}

None

\section{Authorship contribution}

The author is responsible for all content and aspects of the writing and editing.

\section{Conflict of interest}

The author declares no conflicts of interest.

\section{Funding}

This work was not funded.

\section{Consent for publication}

Not applicable.

\section{Availability of data and materials}

Not applicable.

\section{References}

1. Tong JY, Wong A, Zhu D, Fastenberg JH, Tham $\mathrm{T}$. The prevalence of olfactory and gustatory dysfunction in COVID-19 patients: A systematic review and meta-analysis Otolaryngol Head Neck Surg 2020 May 5:194599820926473.

2. Lechien JR, Chiesa-Estomba CM, De Siati $D R$, et al. Olfactory and gustatory dysfunctions as a clinical presentation of mild-tomoderate forms of the coronavirus disease (COVID-19): a multicenter European study. Eur Arch Otorhinolaryngol 2020 Apr 6:1-11.

3. Bilinska K, Butowt R. Anosmia in COVID-19: A Bumpy Road to Establishing a Cellular Mechanism. ACS Chem Neurosci 2020 Aug 5;11(15):2152-2155

4. Jaime-Lara RB, Parma V, Yan CH, Faraji F, Joseph PV. Role of Olfaction in Human Health: A Focus on Coronaviruses. Allergy Rhinol (Providence).

\section{0;11:2152656720928245}

5. Root-Bernstein R. Rethinking molecular mimicry in rheumatic heart disease and autoimmune myocarditis: Laminin, collagen IV, CAR, and B1AR as initial targets of disease. Front Pediatr. 2014; 2: 85.

6. Ma H, Zeng $W$, He $H$, et al. Serum IgA, IgM, and IgG responses in COVID-19. Cell Mol Immunol. 2020; 17(7): 773-775.

7. Butler SE, Crowley AR, Natarajan $\mathrm{H}$, et al. Features and functions of systemic and mucosal humoral immunity among SARSCoV-2 convalescent individuals. Preprint. medRxiv. 2020;2020.08.05.20168971

8. Kanjanaumporn J, Aeumjaturapat S Snidvongs K, Seresirikachorn K, Chusakul S. Smell and taste dysfunction in patients with SARS-CoV-2 infection: A review of epidemiology, pathogenesis, prognosis, and treatment options. Asian Pac J Allergy Immunol 2020; 38(2): 69-77.
9. Root-Bernstein R, Fairweather D. Unresolved issues in theories of autoimmune disease using myocarditis as a framework. J Theor Biol 2015;375:101-123.

Robert Root-Bernstein, PhD

Michigan State University

Department of Physiology

East Lansing

MI 48824

USA

Tel: 1-609-789-3965

E-mail: rootbern@msu.edu

ISSN: 2589-5613 / @2020 The Author(s). This work is licensed under a Creative Commons Attribution 4.0 International License. The images or other third party material in this article are included in the article's Creative Commons license, unless indicated otherwise in the credit line; if the material is not included under the Creative Commons license, users will need to obtain permission from the license holder to reproduce the material. To view a copy of this license, visit http://creativecommons.org/ licenses/by/4.0/ 